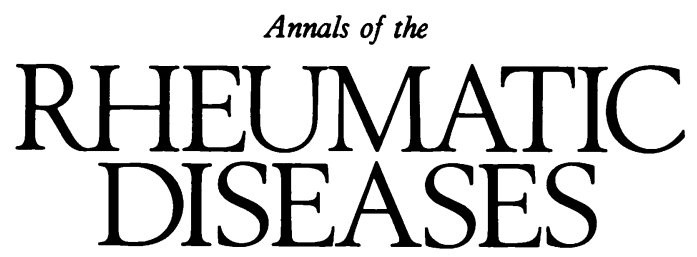

Leader

\title{
Antinuclear antibodies and juvenile chronic arthritis (JCA): search for a specific autoantibody associated with JCA
}

The term 'antinuclear antibodies' refers to a diverse group of autoantibodies which are directed against antigens normally (but not exclusively) found in the nucleus. Within the field of paediatric rheumatology antinuclear antibodies are of considerable interest as they are found in most children with juvenile chronic arthritis (JCA). ${ }^{1}$ The relation between JCA and antinuclear antibodies was first reported over 30 years ago. ${ }^{2}$ A further 14 years elapsed before the clinical importance of these antibodies in predicting the complication of chronic anterior uveitis was recognised. ${ }^{3}$ Antinuclear antibodies are an almost universal finding in the clinical 'syndrome' of early onset pauciarticular JCA with chronic anterior uveitis. It is unlikely, however, that this syndrome has a single cause. Several infectious agents have been implicated in the cause of diseases which are clinically indistinguishable from JCA. ${ }^{4}$ In addition, there may be considerable overlap between JCA and other rheumatic conditions, such as juvenile psoriatic arthritis ${ }^{6}$ and systemic lupus erythematosus. ${ }^{7}$ Probably, chronic childhood arthritis is the 'final common pathway' for many different diseases with different causes, and the term ' $\mathrm{JCA}$ ' covers a heterogeneous group of diseases. If JCA is due to several causes, and if each cause is associated with specific antinuclear antibodies, children with clinically identical disease might be expected to have antibodies of different specificities. It may be illogical to expect one antinuclear antibody specific for JCA. Even the clinically useful splitting of JCA into onset subtypes (pauciarticular, polyarticular, and systemic) may have little biological relevance, and therefore may not correlate with specific antinuclear antibodies. For convenience, we will continue to refer to 'JCA' in this article, and will use the term interchangeably with juvenile rheumatoid arthritis, while recognising that it is unlikely that either term refers to a single disease entity.

Antinuclear antibodies of defined specificities have been strongly associated with other autoimmune diseases, and some have even been implicated in disease pathogenesisfor example, antibodies to double stranded DNA in systemic lupus erythematosus, ${ }^{89}$ and anti-Ro and anti-La in congenital complete heart block. ${ }^{10}$ At the present time little is known about the specificity of antinuclear antibodies in JCA. The aims of this paper are (a) to summarise current knowledge about antinuclear antibodies associated with JCA; $(b)$ to highlight some possible directions for future research; and $(c)$ to suggest avenues for using these antibodies to increase our understanding about the cause, pathogenesis, and even treatment of chronic childhood arthritis. Much of this article is speculative, but hopefully will generate discussion and research which will lead to a better understanding of antinuclear antibodies in general, and those associated with JCA in particular.

\section{Current knowledge about antinuclear antibodies} associated with JCA

Early studies of antinuclear antibodies associated with JCA failed to show the specific autoantibodies which have been associated with other connective tissue diseases-for example, anti-Sm, -SS-A/Ro, -SS-B/La, -RNP, -dsDNA, ssDNA, -RNA, Scl-70, PM-1, or -RAP. ${ }^{11-13}$ The possibility that antinuclear antibodies associated with JCA were directed against histones (structural proteins in the nucleus) was suggested by Rosenberg et al, ${ }^{14}$ but evidence for this was equivocal. ${ }^{15-18}$

More recently, antibodies against histones have been found in $\sim 50 \%$ of patients with JCA. ${ }^{19-21}$ Although in broad agreement, there are important disparities between these studies. Histones from HEp-2 cells were used to demonstrate IgG or IgM antihistone antibodies, against mainly $\mathrm{Hl}$, in $36(42 \%)$ of 86 patients with juvenile rheumatoid arthritis. ${ }^{19}$ No relation was found with uveitis. When chicken erythrocyte histones were used antibodies directed predominantly against histones $\mathrm{Hl}$ and $\mathrm{H} 5$ were found in about half of 51 patients with juvenile rheumatoid arthritis. ${ }^{20}$ There was a weak association between antibodies to histones and uveitis. A third group found that serum samples from $58(48 \%)$ of 121 patients with JCA reacted particularly with $\mathrm{H} 3$ histones, and this correlated strongly with uveitis. ${ }^{21}$ Interestingly, none of the studies reported a significant association between antinuclear antibodies (detected by immunofluorescence) and the presence of antibodies to histones. Antibodies to histones have also been found in children with systemic lupus erythematosus, ${ }^{22}$ as well as children without inflammatory rheumatic disease, ${ }^{23}$ so it remains unclear whether these antibodies are of either diagnostic value or pathogenic significance in JCA. Antibodies against other undefined nuclear proteins have been demonstrated in serum samples from patients with JCA. ${ }^{19} 2425$ Although it has been suggested that an IgG antibody against a $45 \mathrm{kD}$ nuclear protein might identify a subgroup of patients without uveitis, ${ }^{19}$ no specific anti- 
nuclear antibodies have been consistently associated with JCA, its clinical subdivisions, or its complications.

\section{Possible future directions for research} OVERCOMING DIFFICULTIES WITH CURRENT METHODS Can antinuclear antibodies which are specific for JCA be found? The answer to this question may be affected by the wide variety of substrates and techniques used to detect these antibodies. Common substrate sources have included mouse kidney and liver; rat liver, kidney, and stomach; rabbit and calf thymus; fresh beef spleen; chicken erythrocytes; and human epithelial cell lines (HEp-2, HeLa, KB), lymphocytic cell lines (K562, WIL2), and leucocytes. The concentration and nature of nuclear components, and therefore the type of antinuclear antibody detected, may vary depending on the substrate source and the extraction techniques used.

Standard techniques for antinuclear antibody detection include indirect immunofluorescence, indirect immunoenzyme assays, Ouchterlony double diffusion, counter current immunoelectrophoresis, immunoblotting, and enzyme linked immunosorbent assays (ELISA). These techniques vary in their ability to detect antibodies depending on the quantity and nature of the immune complexes formed, and the sensitivity of the system used to detect such complexes. Possibly, further characterisation may depend on a substrate or technique that is not in current use.

Immunoblotting is arguably the most suitable initial procedure for characterising antinuclear antibodies as it provides information on the molecular weights of the putative autoantigens, ${ }^{26}$ and the relevant nuclear antigenautoantibody complex is potentially recoverable from the matrix. In immunoblotting nuclear proteins are separated according to molecular weight by gel electrophoresis, transferred ('blotted') to a solid matrix, and incubated with patients' serum. After washing, any bound human immunoglobulins - that is antinuclear antibodies-are visualised as a 'band' by a labelled antihuman immunoglobulin antibody. ${ }^{27}$ Unfortunately, immunoblotting is subject to considerable interassay variation, making quality control difficult. Van Dam and colleagues reported that the amount of protein recovered after immunoblotting was strongly influenced by transfer and incubation conditions, and ranged from 10 to $65 \%$ of the quantity originally used. ${ }^{28}$

The results of immunoblotting are also affected by differences in the sources, method of extraction, and concentration of the nuclear substrate. When immunoblots using nuclear substrates from two different sources, K562 and rabbit thymus extract, were compared, there was an almost complete lack of concordance in the banding patterns of identical JCA serum samples. ${ }^{25}$ It is likely that comparisons between substrates from other nuclear sources would also yield discordant results. ${ }^{29}$ When the substrate extraction conditions were varied $63 \%$ of antinuclear antibody positive JCA serum samples were found to react with a $0.3 \mathrm{M}$ (but not a 0.1 or $0.5 \mathrm{M}$ ) $\mathrm{NaCl}$ extracted HeLa substrate. ${ }^{24}$ Alterations in the substrate concentration may change the sensitivity of immunoblotting. A new antinuclear antibody specific for adult rheumatoid arthritis was found by using a substrate concentration about fivefold greater than the conventional concentration. ${ }^{30} \mathrm{~A}$ comprehensive (and exhaustive) set of controlled experiments comparing substrates and technical methods will be needed to improve the specificity, sensitivity, and reproducibility of immunoblotting for characterising antinuclear antibodies associated with JCA.

MANIPULATING THE NUCLEAR SUBSTRATE

It is interesting to speculate whether relevant nuclear antigens might be induced by manipulation of the environ- ment and growth conditions of cell lines used for nuclear substrates. Routine assays for antinuclear antibodies such as indirect immunofluorescence of $\mathrm{HEp}-2$ cells, make no attempt to use synchronously cycling cells. During the cell cycle a phase dependent variation in the volume and concentration of the nuclear matrix of the cell occurs. Just before DNA synthesis, for example, the nuclear volume and concentration of non-chromatinic material may increase tenfold (D L Brown, 19th international leucocyte culture conference, BANFF, Alberta, Canada, 1988). Similarly, the nuclear composition is altered by the state of activation of the cell. It is possible that 'phase specific' and 'activity specific' antinuclear antibodies will be found, which might be of relevance to JCA. Indeed, an activated, synchronously cycling cell line was used to delineate antibodies against the proliferating cell nuclear antigen, which is found in about $3 \%$ of patients with systemic lupus erythematosus. ${ }^{31}$

Other manipulations of the cells might include viral infection, exposure to cytokines, and heat stress. Many viruses have been implicated in the cause of JCA. ${ }^{52}$ Viral infection (adenovirus, cytomegalovirus, Epstein-Barr virus) of the HEp-2 cell line has also been shown to induce dramatic changes in the concentration and cellular distribution of nuclear antigens ( $\mathrm{La}$ and $\mathrm{Sm}$ ), perhaps exposing previously 'protected' antigens to the immune system. ${ }^{33}$ Infection might also induce neoantigens, which could be responsible for selecting the antinuclear antibody repertoire. Antibodies to histone $\mathrm{H} 5$ alone have been demonstrated in $10 \%$ of patients with JCA. ${ }^{20}$ Histone $\mathrm{H} 5$ is a variant of $\mathrm{H} 1$ which is unique to non-mammalian species, and is not cross reactive with mammalian protein. On the basis of this finding the authors suggested that 'autoimmunity' in JCA may be initiated by an undiscovered pathogen. Using infected human cell lines as substrate for detection of antinuclear antibodies associated with JCA might yield intriguing results, and similar experiments could be undertaken with high dose cytokines-for example interferon $\gamma,{ }^{33}$ or stress events such as heat shock.

The role of stress proteins in autoimmunity is currently an area of intense research. Autoantibodies to six stress proteins have been described, including histone H2B. Under pathological conditions, such as rheumatoid arthritis, stress proteins can be expressed on the plasma membrane, where they are accessible to the immune system. ${ }^{34}$ Some nuclear antigens-for example, ribonucleoproteins-may only become exposed after brief heat shock, though the temperature may have to exceed physiological levels to induce a significant change. ${ }^{35}$

\section{'NEW' TECHNIQUES FOR DEFINING THE SPECIFICITY OF} ANTINUCLEAR ANTIBODIES

Technical approaches other than immunoblotting may add to our understanding of antinuclear antibodies associated with JCA. The roles of antigen presenting cells and T cells in facilitating the generation of antinuclear antibodies are poorly understood. Functional assays, such as antigen specific lymphocyte proliferation and the use of nuclear antigens to develop lymphocyte clones, may provide information on the mechanism of antinuclear antibody production, and involvement of the cell mediated immune response in this process.

An understanding of the nuclear antigens themselves is obviously crucial. Several autoantigens, including $\mathrm{La}, \mathrm{Sm}$, and the proliferating cell nuclear antigen, have been cloned recently using recombinant DNA technology. Monoclonal antibodies to such antigens have been developed. ${ }^{36} 37$ Comparisons between the monoclonal antibodies and native autoantibodies have been performed with 'epitope mapping' techniques. Such studies have shown that the tertiary 
structure (folded shape) of the native nuclear antigens may be critical to the specificity of the autoantibodies generated. ${ }^{37}$ It follows that any disruption of this shape, such as the protein denaturation commonly used in immunoblotting techniques, may give results which are misleading or uninterpretable.

Molecular biology techniques could be applied using putative antinuclear antibodies associated with JCA to identify their cognate antigens (the nuclear antigens that they recognise) by screening cDNA expression libraries, with subsequent determination of the amino acid sequence and structure of the antigen. This information may be of use not only to standardise testing for antinuclear antibodies associated with JCA but also to define the function of the autoantigen. ${ }^{38}$

\section{Using antinuclear antibodies to increase our understanding of JCA}

INVESTIGATING THE GENETIC BASIS OF JCA

The genetic basis for JCA is unclear. It is rare for JCA to occur in more than one member of the same family. Although there are several well documented HLA associations with the disease, the relative risk of JCA for any particular HLA allele is low. The prevalence of other autoimmune diseases in the families of patients with JCA is increased, ${ }^{39}$ and serological evidence of autoimmunity in these families is common. ${ }^{25}$ In $5 / 20$ families of patients with JCA immunoblot bands of identical molecular weight were shown in both the proband with JCA and one parent. ${ }^{25}$ No parents had concordant banding patterns. These findings support a genetic predisposition towards autoantibody production, but also suggest that disease development is not simply a direct consequence of such autoimmune phenomena.

Previous research has emphasised an association between HLA-DR5 and DRw8, pauciarticular onset JCA, uveitis, and antinuclear antibodies. ${ }^{40}$ These studies could be extended by analysing the major histocompatibility complex associations of antinuclear antibody expression within families of patients with JCA, and might help clarify the genetic basis of JCA. Evidence from other connective tissue diseases supports the possibility of such an association; for example, HLA-DR5 and anti-DNA-topoisomerase I in scleroderma. ${ }^{41}$ Further research into those rare families unlucky enough to contain more than one member with JCA may emphasise associations between particular HLA haplotypes, specific autoantibodies, and clinical features. Such investigation may also highlight the role of environmental factors in antinuclear antibody formation. 4243

\section{IMPROVING THE SUBCLASSIFICATION OF JCA}

At present patients with JCA are categorised by disease onset subtypes. It would be interesting to group patients according to their antinuclear antibody specificity (for example, antihistone $\mathrm{H1}$ ), and then study prospectively the clinical features, complications, and outcome of these groups. Such an approach might improve our understanding of why children with JCA of apparently identical onset have such widely differing disease courses. Information on the constancy of antinuclear antibody specificity throughout the disease course may also result from such studies. It is possible, though hopefully unlikely, that antinuclear antibodies may be found to be irrelevant epiphenomena of JCA, arising by chance in children with abnormal immune responses. In support of this antinuclear antibody titres have not been found to correlate strongly with disease activity, ${ }^{40} 44$ or with evidence of complement activation. ${ }^{45}$

PROSPECTS FOR THE TREATMENT OF JCA

It is highly unlikely that information gained from the study of antinuclear antibodies will be of therapeutic use in the short term. There are several foreseeable prospects for treatment in the future, however. If studies of antinuclear antibodies associated with JCA implicate specific infectious agents in the cause of the disease then appropriate antiinfectious treatment and immunisation may be of use. Removal of specific 'pathogenic antinuclear antibodies', immune complexes, or cells critical to the formation of such autoantibodies, may be possible with selective plasmapheresis or lymphopheresis techniques. Once the molecular nature of the autoantigen is understood, immunisation against the formation of pathogenic antinuclear antibodies may even be possible using peptide competition techniques. ${ }^{4647}$

In conclusion, the study of antinuclear antibodies in patients with JCA is far from complete. At present, tests for these antibodies are clinically useful in helping to highlight those children with JCA who are at particular risk of developing chronic anterior uveitis. Further advances in understanding the specificity of antinuclear antibodies, and the function of their cognate antigens, may come about through improvements in the techniques of antinuclear antibody detection, manipulations of the nuclear substrates used in these techniques, and a greater understanding of the subclassification of JCA. If an association between a specific antinuclear antibody and JCA can be found it will be useful in understanding the basis of the autoimmune process in this disease.

\section{Note added in proof}

Since this article went to press further antinuclear antibody specificities have been associated with JCA. These include high mobility group proteins, ${ }^{48}$ the carboxy terminal segement of histone $\mathrm{Hl},{ }^{49}$ and the protein products of RNA polymerase III. ${ }^{50}$ In addition, studies of synchronously cycling cell substrates have shown that up to $100 \%$ of patients with pauciarticular onset JCA with chronic anterior uveitis react with the chromosomal regions of mitotic cells. ${ }^{51}$ The clinical importance of these findings remains to be elucidated.

Department of Rheumatology,

T R SOUTHWOOD

The Medical School,

University of Birmingham,

Birmingham B15 2TT,

United Kingdom

Division of Rheumatology,

Department of Paediatrics,

The Research Centre,

950 West 28th Avenue,

Vancouver $B C$

Canada V5Z $4 \mathrm{H} 4$

1 Juvenile rheumatoid arthritis. In: Cassidy J T, Petty R E, eds. Textbook of pediatric rheumatology. New York: Churchill Livingstone, 1990: 148-50.

2 Holborow E J, Weir D M, Johnson G D. A serum factor in lupus erythematosus with affinity for tissue nuclei. $B M F$ 1957; ii: 732 .

3 Schaller J G, Johnson G D, Holborow E J. The association of antinuclear antibodies with the chronic iridocyclitis of juvenile rheumatoid arthritis (Still's disease). Arthritis Rhewm 1974; 17: 409-16.

4 Steere A C. Lyme disease. N Engl f Med 1989; 321: 586-96.

5 Chantler J K, Tingle A J, Petty R E. Persistent rubella virus infection associated with chronic arthritis in children. $N$ Engl f Med 1985; 313: 1117-23.

6 Southwood T R, Petty R E, Malleson P N, et al. Psoriatic arthritis in children. Arthritis Rhewo 1989; 32: 1007-13.

7 Ragsdale C G, Petty R E, Cassidy J T, Sullivan D B. The clinical progression of apparent juvenile rheumatoid arthritis to systemic lupus erythematosus. I Rheumatol 1980; 7: 50-5.

8 Raz E, Brezis M, Rosenmann E, Eilat D. Anti-DNA antibodies bind directly to renal antigens and induce kidney dysfunction in the isolated perfused rat kidney. $\mathcal{f}$ Immunol 1989; 142: 3076-82.

9 Tan E M. Do autoantibodies inhibit function of their cognate antigens in vivo? Arthritis Rheum 1989; 32: 924-5.

10 Buyon J P, Winchester R. Congenital complete heart block: a human model of passively acquired autoimmune injury. Arthritis Rheum 1990; 33: 609-14.

11 Alspaugh M A, Miller III J J. A study of specificities of antinuclear antibodies in juvenile rheumatoid arthritis. $\mathcal{7}$ Pediatr 1977; 90: 391-5. 
12 Moore T L, Osborn T G, Weiss T D, et al. Autoantibodies in juvenile arthritis. Semin Arthritis Rhemen 1984; 13: 329-36.

13 Osborn T G, Patel N J, Moore T L, Zuckner J. Use of the HEp-2 cell substrate in the detection of antinuclear antibodies in juvenile rheumatoid arthritis. Arthritis Rhewen 1984; 27: 1286-9.

14 Rosenberg A M, Cordeiro D M, Knause R P. Studies on the specificity of antinuclear antibodies in juvenile rheumatoid arthritis [Abstract]. Arthritis Rhewom 1983; 26 (suppl 4): S57.

15 Brunet C, Craft J, Nakamura M, Pachman L, Athreya B, Hardin J. Identification of nuclear antigens bound by sera from patients with juvenile rheumatoid arthritis [Abstract]. Arthritis Rhewm 1986; 29 (suppl 4): S67.

16 Haynes D C, Gershwin M E, Robbins D L, Miller III J J, Cosca D. Autoantibody profiles in juvenile arthritis. $\mathcal{F} R$ heromatol 1986; 13: 358-63.

17 Saulsbury F T. Antinuclear antibody specificity in -juvenile rheumatoid arthritis [abstract]. Clin Res 1985; 33: 512A.

18 Saulsbury F T. Antibody to ribonucleoprotein in pauciarticular juvenile heumatoid arthritis $\mathcal{F}$ R hermatol $1988,15,295-7$.

19 Malleson P N, Petty R E, Fung M, Candido E P M. Reactivity of antinuclear antibodies with histones and other antigens in juvenile rheumatoid arthritis. Arthritis Rhewn 1989; 32: 919-23.

20 Pauls J D, Silverman E, Laxer R M, Fritzler M J. Antibodies to histones H1 and $\mathrm{HS}$ in sera of patients with juvenile rheumatoid arthritis. Arthritis Rhewom 1989; 32: 877-83.

21 Ostensen M, Fredriksen K, Kass E, Rekvig O-P. Identification of antihistone antibodies in subsets of juvenile rheumatoid arthritis Amn Rherum Dis 1989; 48: 114-7.

22 Delgado E A, Malleson P N, Pirie G E, Petty R E. The pulmonary manifestations of childhood onset systemic lupus erythematosus. Semin Arthritis Rhew 1990; 19: 285-93.

23 Cabral D A, Petty R E, Fung M, Malleson P N. Antinuclear antibodies (ANA) in children without identifiable inflammatory rheumatic disease. Arthritis Rhewom 1990; 33: R10-22W.

24 Haber P L, Osborn T G, Moore T L. Antinuclear antibody in juvenile rheumatoid arthritis sera reacts with $50-40 \mathrm{kDa}$ antigen(s) found in HeLa nuclear extracts. I R heumatol 1989; 16: 949-54.

25 Southwood T R, Roberts-Thomson P J, Ahern M J, et al. Autoantibodies in patients with juvenile chronic arthritis and their immediate family relatives. Ann Rhewn Dis 1990; 49: 968-72.

26 Westgeest A A A, van den Brink H G, de Jong J, Swaak A J G, Smeenk R J T. Routine testing for antinuclear antibodies: a comparison of immunofluorescence, counterimmunoelectrophoresis and immunoblotting. 7 Autoimomun 1988; 1: 159-70.

27 Towbin H, Gordon J. Immunoblotting and dot immunobinding-current status and outlook. F Immenol Methods 1984; 72: 313-40.

28 Van Dam A P, van den Brink H G, Smeenk R J T. Technical problems concerning the use of immunoblots for the detection of antinuclear antibodies. F Immunol Methods 1990; 129: 63-70.

29 Collins R J, Neil J C, Druery L N, Wilson R J. Detection of antibodies to extractable nuclear antigens using calf thymus and rabbit thymus. A comparative study of 1000 consecutive anti-nuclear antibody positive patients. F Immunol Methods 1989; 116: 53-7.

30 Hassfeld $W$, Steiner G, Hartmuth $K$, et al. Demonstration of a new antinuclear antibody (anti-RA33) that is highly specific for rheumatoid arthritis. Arthritis Rheum 1989; 32: 1515-20.

31 Takasaki Y, Deng J S, Tan E M. A nuclear antigen associated with cell proliferation and blast transformation. Its distribution in synchronised proliferation and blast transformation.
cells. $f$ Exp Med 1981; 154: 1899-909. 32 Petty R E, Tingle A J. Arthritis and viral infection. J Pedigtr 1988; 113:

33. Baboonian P J, Venables P J W, Booth J, Williams D G, Roffe L M, Maini $R$ N. Virus infection induces redistribution and membrane localization of the nuclear antigen La(SS-B): a possible mechanism for autoimmunity. Clin Exp Immeronol 1989; 78: 454-9.

34 Winfield J B. Stress proteins, arthritis, and autoimmunity. Arthritis Rheum 1989; 32: 1497-504.

35 Mahl P, Lutz Y, Puvion E, Fuchs J-P. Rapid effect of heat shock on two heterogeneous nuclear ribonucleoprotein-associated antigens in HeLa cells. f Cell Biol 1989; 109: 1921-35.

36 Chan E K L, Tan E M. Human autoantibody-reactive epitopes of SS-B/La are highly conserved in comparison with epitopes recognized by murine monoclonal antibodies. 7 Exp Med 1987; 166: 1627.

37 Huff J P, Roos G, Peebles C L, Houghten R, Sullivan K F, Tan E M. Insights into native epitopes of proliferating cell nuclear antigen using recombinant DNA protein products. $f$ Exp Med 1990; 172: 419-29.

38 Tan E M, Chan E K L, Sullivan K F, Rubin R L. Antinuclear antibodies (ANAs): diagnostically specific immune markers and clues towand the understanding of systemic autoimmunity. Clin Immonol Imemunopathol
1988; 47: 121-41.

39 Church J L, Bernstein B, Church J A, Hanson V. Familial prevalence of immunologically-mediated diseases (IMD) in juvenile rheumatoid arthritis (IRA) [abstract]. Arthritis Rhewen 1983; 26 (suppl): S85.

40 Leak A M, Ansell B M, Burman S J. Antinuclear antibody studies in juvenile rheumatoid arthritis. Arch Dis Child 1986; 61: 168-72.

41 Genth E, Mierau R, Genetzky P, et al. Immunogenetic associations of scleroderma-related antinuclear antibodies. Arthritis Rhewem 1990; 33: 657-65.

42 Buchanan W W, Boyle J A, Greig W R, et al. Occurrence of autoantibodies in healthy twins. Clin Exp Imemunol 1967; 2: 803-11.

43 Aho K, Sistonen P, Takala J, Sievers $K$. Genetics of autoantibodies in relation to disease. An epidemiological study of two population series. Acta Med Scand 1982; 211: 213-8.

44 Rosenberg A M. The clinical associations of antinuclear antibodies in juvenile heumatoid arthritis. Clin Immumol Imomunopathol 1988; 49: 19-27.

45 Miller III J J, Olds L C, Silverman E D, et al. A search for correlation between autoantibodies and complement activation in juvenile arthritis [abstract]. Arthritis Rhewen 1987; 30 (suppl 4): S126.

46 Adorini L, Appella E, Doria G, Cardinaux F, Nagy Z A. Competition for antigen presentation in living cells involves exchange of peptides bound by antigen presentation in living cells involves exchange

47 Adorini L, Nagy Z A. Peptide competition for antigen presentation. Immunol Today 1990; 11: $21-4$

48 Witteman B, Neuer G, Michels $H$, et al. Autoantibodies to nonhistone chromosomal proteins HMG-1 and HMG-2 in sera of patients with juvenile rheumatoid arthritis. Arthritis Rhewem 1990; 33: 1378-83.

49 Monestier M, Losman J A, Fasy T M, et al. Antihistone antibodies in antinuclear antibody-positive juvenile arthritis. Arthritis Rheum 1990; 33: 1836-41.

50 Szer W, Sierakowska $H$, Szer I S. Antinuclear antibody profile in juvenile theumatoid arthritis. I Rhewmatol 1991; 18: 401-8.

51 Rosenberg A M, Gilmer S M. Cell cycle specific patterns of autoantibody reactivity in juvenile rheumatoid arthritis (JRA) [abstract]. Proceedings,
Park City III 1991: 1-29. 